\title{
Pristionchus pacificus genetic protocols ${ }^{*}$
}

\author{
Andre Pires da Silva ${ }^{\S}$, Department of Biology, University of Texas at \\ Arlington, Arlington, TX 76019-0498 USA
}

\section{Table of Contents}

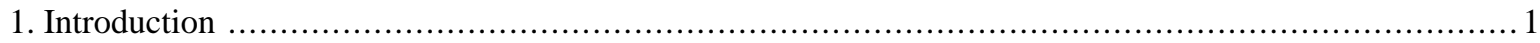

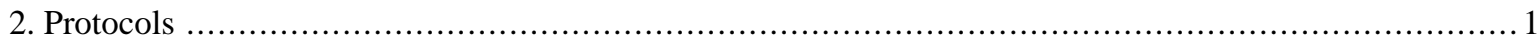

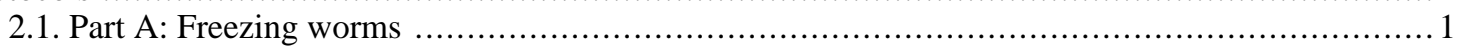

2.2. Part B: Mutagenesis .......................................................................... 2

2.3. Part C: Construction of deletion libraries to generate $P$. pacificus gene knock-outs ................. 4

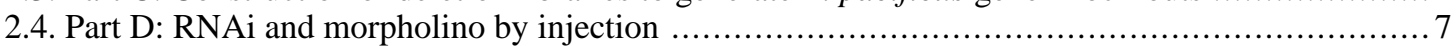

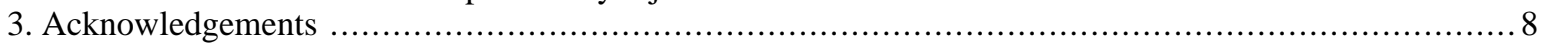

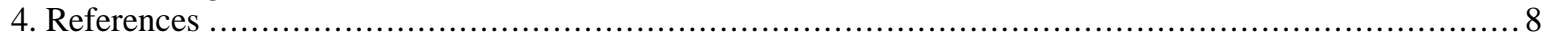

\section{Introduction}

The diplogastrid nematode Pristionchus pacificus has been recently established as a new genetic model system for evolutionary studies. Forward and reverse genetics tools have been developed to allow detailed comparisons to the rhabditid nematode $C$. elegans. $P$. pacificus has distinctive body morphology and diverges in development both at the cellular and molecular level when compared to $C$. elegans (see Evolution of development in nematodes related to $C$. elegans). Despite these differences, $P$. pacificus shares many traits with $C$. elegans that are of advantage for genetic analyses: it is hermaphroditic, has a small genome size (160 Mb), small number of chromosomes (haploid set with 5 autosomes and 1 sex chromosome), short life-cycle (4 days at $20^{\circ} \mathrm{C}$ ), and produces large brood sizes (150-200 eggs). Similarly to C. elegans, P. pacificus has 4 larval stages (J1-J4). However, the first larval stage molts within the eggshell (Sudhaus et al., 2003).

\section{Protocols}

\subsection{Part A: Freezing worms}

$P$. pacificus can be frozen in liquid nitrogen, although with lower efficiency than $C$. elegans. It was observed that the addition of calcium to the M9 dramatically increased P. pacificus freezing efficiency. As for $C$. elegans, $P$.

\footnotetext{
*Edited by Ralf J. Sommer. WormMethods editor, Victor Ambros. Last revised June 29, 2006. Published July 17, 2006. This chapter should be cited as: Pires da Silva, A. Pristionchus pacificus genetic protocols (July 17, 2006), WormBook, ed. The C. elegans Research Community, WormBook, doi/10.1895/wormbook.1.114.1, http://www.wormbook.org.

Copyright: (C) 2006 Andre Pires da Silva. This is an open-access article distributed under the terms of the Creative Commons Attribution License, which permits unrestricted use, distribution, and reproduction in any medium, provided the original author and source are credited.

§ To whom correspondence should be addressed. E-mail: apires@uta.edu
} 
pacificus early hatched larvae are most likely to survive freezing and thawing. Some modifications were added to the common C. elegans freezing protocol to increase efficiency (Protocol 1).

\section{Protocol 1. Freezing P. pacificus}

\section{Equipment and Reagents}

- Plates with Nematode Growth Medium (NGM) $15 \mathrm{~g}$ agar, $2.4 \mathrm{~g} \mathrm{NaCl}, 2 \mathrm{~g}$ Tryptone, $2.72 \mathrm{~g} \mathrm{KH}_{3} \mathrm{PO}_{4}, \mathrm{H}_{2} \mathrm{O}$ to 1 liter. Autoclave, let the solution cool to $60^{\circ} \mathrm{C}$. Add $0.8 \mathrm{ml} 1 \mathrm{M} \mathrm{CaCl}_{2}, 0.8 \mathrm{ml}$ cholesterol (stock solution: $2.5 \mathrm{~g}$ in $500 \mathrm{ml}$ ethanol), $0.8 \mathrm{ml} 1 \mathrm{M} \mathrm{MgSO}_{4}$ ]. Add $250 \mu \mathrm{l}$ of $E$. coli OP50 to each $6 \mathrm{~cm}$ diameter plate.

- $\quad$ M9 Buffer [Protocol 6 (see Maintenance of C. elegans)] containing $1 \mathrm{mM} \mathrm{CaCl}_{2}$.

- Soft Agar Freezing Solution [0.58 g NaCl, $0.68 \mathrm{~g} \mathrm{KH}_{2} \mathrm{PO}_{4}, 24 \mathrm{ml}$ glycerol, $0.56 \mathrm{ml}, 0.4 \mathrm{~g}$ agar, $\mathrm{H}_{2} \mathrm{O}$ to $100 \mathrm{ml}$ (autoclave). Add $3 \mathrm{ml}$ of $\left.0.1 \mathrm{M} \mathrm{MgSO}_{4}\right]$

- $1.8 \mathrm{ml}$ cryotube vials

1. Grow worms on about 10 NGM plates until one day beyond the time the plates are just cleared of bacteria. Heat-shock worms on the plates at $30^{\circ} \mathrm{C}$ for $2-3$ hours.

2. Wash each plate with $2 \mathrm{ml} \mathrm{M} 9$, and transfer to a sterile $15 \mathrm{ml}$ tube. Centrifuge worms at $1500 \times \mathrm{g}$ for 5 minutes, and combine all worms in one tube in $3 \mathrm{ml}$ of M9. Add an equal volume of Freezing Solution. Mix well.

3. Aliquot $1 \mathrm{ml}$ of the mixture into $1.8 \mathrm{ml}$ cryovials labeled with the strain name and date.

4. Put cryovials into a Styrofoam tube tray and cover with another (an alternative is to take a Nalgene Cryo $1^{\circ} \mathrm{C}$ Freezing Container filled with $100 \%$ isopropyl alcohol). Fasten the racks with a rubber band, enclosing the samples inside the box. This ensures a slow constat rate of cooling.

5. Place the box at $-80^{\circ} \mathrm{C}$ for at least one day.

6. On the following day, once completely frozen, move the vials to the permanent location in a liquid nitrogen tank.

\subsection{Part B: Mutagenesis}

Ethyl methanesulfonate (EMS) has been widely used in P. pacificus to isolate a wide variety of mutants with defects in the egg-laying system, muscle, sex determination, dauer formation, behaviour, and gonad formation (Protocol 2). The protocol for EMS mutagenesis used is the same as for C. elegans (Brenner, 1974). For mutagenizing P. pacificus with psoralen, however, some modifications were introduced (Protocol 3).

\section{Protocol 2. EMS mutagenesis}

Caution: EMS is a very strong mutagen and should be handled in a fume hood. All materials (gloves, pipettes, tips) that have been in contact with this mutagen should be treated with $1 \mathrm{~N} \mathrm{NaOH}$ to inactive the EMS.

\section{Equipment and Reagents}

- $\quad$ M9 Buffer [Protocol 6 (see Maintenance of C. elegans)]

- EMS (ethyl methanesulfonate; Sigma, cat no. M-0880)

- Well fed, young adult $P$. pacificus worms

- $\quad$ NGM plates seeded with E. coli OP50 (to prepare NGM plates, see Protocol 1). 
1. Wash the worms from 4-5 $6 \mathrm{~cm}$ diameter plates using $2 \mathrm{ml}$ of $\mathrm{M} 9$ for each plate. Collect in a $15 \mathrm{ml}$ tube.

2. Centrifuge for 5 minutes at $1500 \times \mathrm{g}$ and resuspend the worms in $2 \mathrm{ml} \mathrm{M} 9$.

3. Add $20 \mu \mathrm{l}$ of EMS into another tube containing $2 \mathrm{ml}$ of M9. Swirl the tube until the EMS has dissolved.

4. Add the EMS solution to the worms (this concentration of EMS corresponds to $47 \mathrm{mM}$ ). Incubate the worms at $20^{\circ} \mathrm{C}$ for 3.5 hours in horizontal position, on a rocker at low speed (40 UPM).

5. Incubate for $30 \mathrm{~min}$ in a vertical position to let worms sink.

6. Remove as much supernatant as possible. Discard the supernatant to a container with $1 \mathrm{~N} \mathrm{NaOH}$ to inactivate the EMS.

7. Wash the worms 3 times with $5 \mathrm{ml}$ of $\mathrm{M} 9$, and centrifuge each time at $1500 \times \mathrm{g}$ for $5 \mathrm{~min}$.

8. Resuspend the worms in $500 \mu \mathrm{l}$ of M9 and dispense them onto 2 NGM plates with OP50.

9. After the solution has soaked in the plate, pick moving J4 animals to new plates.

10. Depending on the mutation of interest (dominant, recessive, maternal effect), pick animals of the relevant generation onto fresh plates, and screen for desired mutant phenotypes.

\section{Protocol 3. Psoralen mutagenesis (modified from Yandell et al., 1994)}

\section{Equipment and Reagents}

- M9 Buffer [Protocol 6 (see Maintenance of C. elegans)]

- $3 \mathrm{mg} / \mathrm{ml}$ TMP solution in DMF (Trioxsalen; Sigma, cat no. T6137; 4,5',8-Trimethylpsoralen)

- Well fed, young adult P. pacificus worms

- Unseeded and seeded NGM agar plates (to prepare NGM plates, see Protocol 1).

- Long-wave ultraviolet (UV) source (365 nm; Model UVL-21 Blak-Ray lamp, UVP, Fisher Scientific cat no. 11-984-40)

- UV intensity meter (Model J-221, UVP)

- Rocker

1. Wash the worms from $4-56 \mathrm{~cm}$ diameter plates using $2 \mathrm{ml}$ of $\mathrm{M} 9$ for each plate. Collect in a $15 \mathrm{ml}$ tube.

2. Using M9 buffer, wash worms off NGM plates, and combine in a $15 \mathrm{ml}$ tube.

3. Wash 2 times with M9, each time pelleting worms at $1500 \times \mathrm{g}$ for 5 minutes.

4. Remove as much liquid as possible and resuspend in $30 \mu \mathrm{g} / \mathrm{ml}$ of TMP

- e.g.: $20 \mu \mathrm{l}$ of TMP $(3 \mathrm{mg} / \mathrm{ml})$ in $2 \mathrm{ml}$ of M9

- Note: the worms should be resuspended in about 10 times their volume

5. Wrap the tube in aluminum foil and incubate the worms for 15 minutes at room temperature on a rocker at low speed (40 UPM). Afterwards, incubate for $5 \mathrm{~min}$ at a vertical position to let worms sink. 
6. Remove worms with a Pasteur pipette and place them in an unseeded worm agar plate at $20-25^{\circ} \mathrm{C}$. Wrap the plate in aluminum foil and let excess TMP to soak into the plate.

7. Calibrate the distance between the long-wave UV source and the plate using the UV intensity meter. Irradiate the worms for 50 seconds at $500 \mu \mathrm{W} / \mathrm{cm}^{2}$ (the distance between the plate and the UV lamp is about $10 \mathrm{~cm}$ ).

8. Keep the worms in the dark for 5 hours.

9. Transfer worms to seeded plates.

\subsection{Part C: Construction of deletion libraries to generate $P$. pacificus gene knock-outs}

A powerful method to isolate $C$. elegans mutants in a gene of interest for which sequence information is available is by chemical mutagenesis followed by polymerase chain reaction (PCR). The generation of knockouts in a high throughput manner by using deletions in a library of worms has proven very successful for $C$. elegans. The protocol adopted for $P$. pacificus does not include the freezing of the library, since the efficiency of recovery following freezing of P. pacificus is too low (Protocol 4). The library comprises 1296 -well microtiter plates and includes the arrayed progeny of nearly $5 \times 10^{5} \mathrm{~F} 1$ animals representing $10^{6}$ mutagenized genomes. Worms are grown in plates until the food is exhausted, generating, on the average, $100 \mathrm{~F} 2$ progeny per F1 animal.

\section{Protocol 4. Deletion library}

\section{Equipment and Reagents}

- M9 Buffer [Protocol 6 (see Maintenance of C. elegans)]

- Basic hypochlorite solution: $30 \mathrm{ml} 0.1 \mathrm{M} \mathrm{NaCl}, 5 \mathrm{ml} \mathrm{NaOH} 5 \mathrm{M}$ and $10 \mathrm{ml} 6 \%$ Sodium hypochlorite.

- Wild type worms

- 130 NGM plates (10 cm diameter) seeded with $1 \mathrm{ml}$ of OP50 (to prepare NGM plates, see Protocol 1).

- 1200 NGM plates ( $6 \mathrm{~cm}$ diameter) seeded with $100 \mu \mathrm{l}$ of OP50.

- 12-well NGM plates seeded with $50 \mu 1$ of OP50.

- $20 \mathrm{ml} 10 \mathrm{X}$ lysis buffer $\left[10 \mathrm{ml} 1 \mathrm{M} \mathrm{KCl}, 2 \mathrm{ml} 1 \mathrm{M}\right.$ Tris $\mathrm{pH} 8.2,0.5 \mathrm{ml} 1 \mathrm{M} \mathrm{MgCl}_{2}, 0.9 \mathrm{ml} \mathrm{NP}-40,0.9 \mathrm{ml}$ Tween-20, fill to $20 \mathrm{ml}$ with water]

- Proteinase $\mathrm{K}(\mathrm{ptnK}) 10 \mathrm{mg} / \mathrm{ml}$

- MicroAmp Clear Adhesive films (AB Appplied Biosystems, Part 4306311)

- Oven $65^{\circ} \mathrm{C}$

- Refrigerated incubator at $12^{\circ} \mathrm{C}$

- $1.2 \mathrm{ml}$ 96-well plates

- $200 \mu 1$ 96-well plates

- $10 \mathrm{X}$ yellow loading dye (6 $\mathrm{g}$ Ficoll, $30 \mathrm{mg}$ Tartrazine, to $30 \mathrm{ml}$ with water) 


\subsubsection{Designing primers for the gene of interest}

Target a region of around $1.5 \mathrm{kbp}(1.0-2.5 \mathrm{kbp})$, with nested oligonucleotides of around $20 \mathrm{bp}$ (annealing temperature of $60^{\circ} \mathrm{C}$ ). The larger the region targeted, the more difficult it is to detect small mutations in agarose gels. The smaller the region, the more difficult it is to find a deletion that happens to have occurred between the primers.

\subsubsection{Growth synchronization}

1. Transfer freshly starved larvae from $106 \mathrm{~cm}$ diameter plates to $1510 \mathrm{~cm}$ diameter plates seeded with $1 \mathrm{ml}$ of OP50 per plate. Incubate at $25^{\circ} \mathrm{C}$ (or $20^{\circ} \mathrm{C}$ ) until plates are full of eggs.

2. Transfer worms and eggs to a $50 \mathrm{ml}$ Falcon tube with $\mathrm{M} 9$ and centrifuge for 5 minutes at $1300 \mathrm{X} \mathrm{g}$. Discard the supernatant. Add $30 \mathrm{ml}$ of basic hypochlorite solution and incubate at room temperature for about 4 minutes. Collect the eggs by centrifugation $(2000 \times \mathrm{g}, 5 \mathrm{~min})$.

3. Wash the eggs 2 times with $30 \mathrm{ml}$ of water and 1 time with $30 \mathrm{ml}$ of $\mathrm{M} 9$ buffer. Leave the worms to hatch overnight in the buffer or in a $10 \mathrm{~cm}$ unseeded NGM plate.

4. The next day, pipet $10 \mu \mathrm{l}$ of the suspension onto each of three plates and count to determine titer. The total

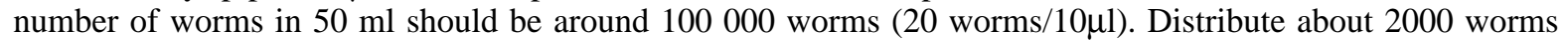
per plate onto 50 seeded $10 \mathrm{~cm}$ NGM plates.

\subsubsection{Mutagenesis}

5. Culture synchronized culture of worms for about 52 hours at $20^{\circ} \mathrm{C}$. Follow protocol 3 for TMP/UV mutagenesis. After mutagenesis, plate the worms on 50 fresh seeded $10 \mathrm{~cm}$ NGM plates, with 2000 worms/plate.

\subsubsection{Plating the library}

6. After a couple of days, when P0s have laid the F1 eggs, bleach the $5010 \mathrm{~cm}$ plates (as in part B, 2) and leave the eggs in $50 \mathrm{ml}$ of M9 buffer overnight.

7. The following day, count the number of L1 worms. Distribute about $400 \mathrm{~F} 1 \mathrm{~s} / \mathrm{small}$ plate (total $12006 \mathrm{~cm}$ plates).

8. Wait one generation, until the F2 eggs have hatched. Wash plates by adding $800 \mu 1$ of water and transferring $150 \mu \mathrm{l}$ of the $\mathrm{L} 1$ suspension into a $1.2 \mathrm{ml}$ 96-well plate (to avoid mistakes, leave the yellow tip inside the well). This step will take about half an hour/plate; in total it will result in $12 \times 96$-well plates. Leave the washed plates at RT until they dry. Then transfer them to $12^{\circ} \mathrm{C}$.

9. Add $150 \mu \mathrm{l}$ of lysis buffer + proteinase $\mathrm{K}(120 \mu \mathrm{g} / \mathrm{ml})$ to each well of the $1.2 \mathrm{ml}$ 96-well plates, seal them with MicroAmp Clear Adhesive films and incubate them first at $-80^{\circ} \mathrm{C}$ for 2 hours and then at $65^{\circ} \mathrm{C}$ overnight with shaking.

10. The following morning, centrifuge the 96 -well plates for $10 \mathrm{~min}$ at $4000 \mathrm{rpm}$.

11. Transfer $150 \mu \mathrm{l}$ of the suspension into a $200 \mu \mathrm{l}$ 96-well plate and inactivate the proteinase $\mathrm{K}$ at $95^{\circ} \mathrm{C}$ for 10 minutes. The remaining $150 \mu \mathrm{l}$ should be stored at $-80^{\circ} \mathrm{C}$.

12. Pool the rows and columns from each of the 12 plates by combining $75 \mu \mathrm{l}$ of each of the wells into a single 1.2 $\mathrm{ml}$ 96-well plate. For example, pool wells A1 of all 12 plates into the position A1 of the $1.2 \mathrm{ml} 96$-well plate. Repeat this procedure for each well, making a total of 96 pools. This is the master plate with pooled DNA.

\subsubsection{Screening the library by PCR}

13. Take $5 \mu \mathrm{l}$ as template for a $20 \mu \mathrm{l}$ PCR reaction. It is necessary to perform nested PCR. For the $2^{\circ}$ round, use 1 $\mu \mathrm{l}$ of the $1^{\circ}$ round. 
a. Example for PCR mix:

\begin{tabular}{|c|c|}
\hline $1^{\mathrm{st}} \underline{\mathrm{PCR} \text { round: [final Volume } 10 \mu \mathrm{l}]}$ & \\
\hline$\overline{\mathrm{H}}_{2} \mathrm{O}$ & $1.7 \mu 1$ \\
\hline dNTP (10 mM each of dATP, dCTP, dGTP, dTTP) & $0.2 \mu \mathrm{l}$ \\
\hline forward primer $(10 \mu \mathrm{M})$ & $0.5 \mu 1$ \\
\hline reverse primer $(10 \mu \mathrm{M})$ & $0.5 \mu 1$ \\
\hline Buffer $5 \mathrm{X}$ & $2.0 \mu 1$ \\
\hline $\operatorname{Taq}(5 \mathrm{U} / \mu \mathrm{l})$ & $0.1 \mu \mathrm{l}$ \\
\hline DNA (pooled Library) & $5.0 \mu 1$ \\
\hline $94^{\circ} \mathrm{C}$ for $2 \mathrm{~min}$. & \\
\hline $94^{\circ} \mathrm{C}$ for $30 \mathrm{sec}$. & \\
\hline $58^{\circ} \mathrm{C}$ for $20 \mathrm{sec} .35$ cycles & \\
\hline $72^{\circ} \mathrm{C}$ for $3 \mathrm{~min}$. & \\
\hline $72^{\circ} \mathrm{C}$ for $6 \mathrm{~min}$. & \\
\hline 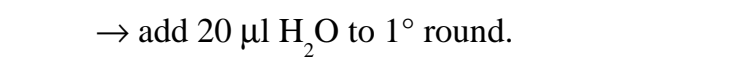 & \\
\hline$\underline{2}^{\underline{\text { nd }}} \underline{\text { PCR round: [final Volume } 10 \mu \mathrm{l}]}$ & \\
\hline $\mathrm{H} \mathrm{O}$ & $3.7 \mu 1$ \\
\hline dNTP (10 mM each of dATP, dCTP, dGTP, dTTP) & $0.2 \mu 1$ \\
\hline forward primer $(10 \mu \mathrm{M})$ & $0.5 \mu \mathrm{l}$ \\
\hline reverse primer $(10 \mu \mathrm{M})$ & $0.5 \mu \mathrm{l}$ \\
\hline Buffer 5X & $2.0 \mu 1$ \\
\hline $\operatorname{Taq}(5 \mathrm{U} / \mu \mathrm{l})$ & $0.1 \mu 1$ \\
\hline yellow Loading dye & $2.0 \mu \mathrm{l}$ \\
\hline DNA (1:3 diluted) & $1.0 \mu \mathrm{l}$ \\
\hline
\end{tabular}

Same cycling conditions as $1^{\text {st }}$ round.

14. Select samples which show bands that are smaller than the wild-type for further tests. Determine the precise address of the candidate sample by repeating the PCR using $5 \mu \mathrm{l}$ of the corresponding well of each of the twelve 96 -well plates (200 $\mu 1$ 96-well plates). This will give the number of the plate (2-A5, for example).

\subsubsection{Sib selection}

15. Resuspend the original plate in $50 \mathrm{ml}$ water or $\mathrm{M} 9(50 \mathrm{ml}$ Falcon tube). Count the number of worms $/ \mu 1$, by pippeting 3 times $10 \mu 1$ into a plate. Calculate the average of worm/ $\mu$ l.

16. Dispense 50 worms into the wells of 8,12 -well plates. The remaining worms (which were not dispensed) should be centrifuged and put back in the original plate, without bacteria. Keep this plate at $12^{\circ} \mathrm{C}$.

17. Culture the worms at $20^{\circ} \mathrm{C}$ for 5 days. Harvest a portion of each well by washing with $300 \mu 1$ of water. Transfer $75 \mu \mathrm{l}$ of the suspension into a $1.2 \mathrm{ml} 96$-well plate, plus $75 \mu \mathrm{l}$ lysis buffer with ptnK. Incubate overnight at $65^{\circ} \mathrm{C}$ with shaking. The agar plates with worms should be kept at $12^{\circ} \mathrm{C}$.

18. Transfer $100 \mu \mathrm{l}$ to a $200 \mu \mathrm{l}$ 96-well plate.

19. Inactivate the ptnK by incubating the 96 -well plate at $95^{\circ} \mathrm{C}$ for 15 minutes.

20. Screen the plate by PCR ( $5 \mu \mathrm{l}$ as template), identify the plate and repeat procedure by dispensing $96 \times 15$ worms/plate.

21. Repeat procedure above with 5 worms/plate and later 1 worm/plate. 


\subsection{Part D: RNAi and morpholino by injection}

The possibility of rapidly knocking-down genes by RNA interference (RNAi), together with the availability of the $C$. elegans genome sequence, stimulated the study of gene function in a global scale (see Reverse genetics). Currently there are three different ways of delivering double-stranded RNA (dsRNA) into C. elegans: injection, soaking and feeding. Preliminary experiments with P. pacificus indicate that RNAi works when injecting dsRNA into the gonad (personal observation). The conditions used for dsRNA preparation and injection were basically the same as described for C. elegans (see Reverse genetics). The injection of a 1081 bp Ppa-tra-1 dsRNA, for instance, resulted in $20 \%(\mathrm{n}=346)$ progeny with the transformer phenotype. For genes involved in vulva development, however, the efficiency of the RNAi seems to be much lower (Zheng and Sommer, personal communication). Similar observations have been made with vulva genes in C. elegans (Chen et al., 2004). Another knockdown technology, using morpholino oligonucleotides, has proven robust for P. pacificus (Protocol 5) (Pires-daSilva et al., 2004; Zheng et al., 2005). Morpholino-oligonucleotides, widely used for knocking down genes in other model systems (e.g., sea urchin, zebrafish), are modified oligonucleotides that efficiently block the translation or splicing of specific mRNAs. The properties of morpholino oligonucleotides, which combine nuclease-resistance, water-solutility and high specificity, are of major advantage. However, the injection of morpholinos causes a high rate of lethality in the P. pacificus F1 progeny (about 50\%). When selecting oligo sequences, it is recommended to design at least two non-overlapping oligos. In this way, the consistency of the resulting phenotype can be tested. A good target sequence has minimal mRNA secondary structure and includes the translational start codon and/or the 5'UTR region.

\section{Protocol 5. Injection of morpholino oligonucleotides}

\section{Equipment and Reagents}

- Agarose

- Glass coverslips $(22 \times 50)$

- Tips for injection Microloader (Eppendorf 5242956.003)

- Light mineral oil (Sigma M-3516)

- Glass thin filaments $1.0 \mathrm{~mm}$ (World Precision Instruments)

- Transjector (Eppendorf 5246)

- Micropippete puller

- Inverted microscope (Zeiss, Axiovert 135)

- Morpholino oligonucleotides (Gene Tools)

1. Prepare $5 \mathrm{ml}$ of $2 \%$ agarose in water, and melt it in the microwave.

2. Drop the melted agarose on to a coverslip. Put another coverslip on top. Repeat this procedure for 10 more pairs of coverslips.

3. Separate the two coverslips and leave the agarose pad in an $80^{\circ} \mathrm{C}$ drying oven for one hour.

4. Dissolve the oligonucleotide to $100 \mu \mathrm{M}$ in water.

5. Pull a glass thin filament with the needle puller (the tip of the needle should taper quickly and smoothly).

6. Load about $500 \mu \mathrm{l}$ of the morpholino into the needle using Microloader tips. To discard bubbles accumulating in the tip of the needle, hold the loaded needle in vertical position for a few minutes.

7. Attach the needle to the transjector. To break the tip of the needle, rub the end of the tip against a thin glass bar immersed in light mineral oil. Monitor the flow of liquid out of the needle under the $40 \mathrm{X}$ objective. 
8. Add a drop of the light mineral oil to the agarose pad. Pick a few worms and place them into the oil. Gently force the worms to the agarose pad with the wormpick, so that the entire body of the worm sticks to the pad.

9. After aligning the needle with the worms, move the gliding stage against the tip of the needle. In this way the needle will penetrate the cuticle of the worm and reach the gonad. Apply pressure to expel the morpholino solution into the gonad.

10. Recover the worms from the agarose pad by adding a drop of M9 buffer onto the surface of the oil. Transfer worms to a freshly seeded plate with a mouth pipette.

\section{Acknowledgements}

Andre Pires da Silva is funded by NSF grant IOB\#0615996.

\section{References}

Brenner, S. (1974). The genetics of Caenorhabditis elegans. Genetics 77, 71-94. Abstract

Chen, N., and Greenwald, I. (2004). The lateral signal for LIN-12/Notch in C. elegans vulval development comprises redundant secreted and transmembrane DSL proteins. Dev. Cell 6, 183-192. Abstract Article

Pires-daSilva, A., and Sommer, R.J. (2004). Conservation of the global sex determination gene tra-1 in distantly related nematodes. Genes Dev. 18, 1198-1208. Abstract Article

Sudhaus, W., and Furst von Lieven, A. (2003). A phylogenetic classification and catalogue of the Diplogastridae (Secernentea). J. Nemat. Morphol. Syst. 6, 43-90.

Yandell, M.D., Edgar, L.G. et al. (1994). Trimethylpsoralen induces small deletion mutations in Caenorhabditis elegans. Proc. Natl. Acad. Sci. USA 91, 1381-1385. Abstract

Zheng, M., Messerschmidt, D. et al. (2005). Conservation and diversification of Wnt signaling function during the evolution of nematode vulva development. Nat. Genet. 37, 300-304. Abstract Article 